\title{
Sleeping Sickness Pathogen (Trypanosoma brucei) and Natural Products: Therapeutic Targets and Screening Systems
}

Author

Affiliation
Véronique Hannaert

Research Unit for Tropical Diseases, de Duve Institute and Laboratory of Biochemistry, Université catholique de Louvain, Brussels, Belgium

\section{Key words \\ - Trypanosoma brucei \\ - Trypanosomatidae \\ - sleeping sickness \\ - natural products \\ - drug targets}

\section{Abstract \\ $\nabla$}

Trypanosoma brucei is the causative agent of human African trypanosomiasis (sleeping sickness) which is fatal if left untreated. This disease occurs in 36 African countries, south of the Sahara, where 60 million people are at risk of acquiring infection. The current chemotherapy relies on only four drugs, three of which were developed more than 60 years ago. These drugs have many limitations, ranging from oral inabsorption, acute toxicities, short duration of action and the emergence of trypanosomal resistance. Despite decades of use of most of the current trypanocides, little is known about their mode of action. That

\section{Introduction}

$\nabla$

Human African trypanosomiasis (HAT) or sleeping sickness is an infectious disease transmitted

received June 2, 2010 revised August 31, 2010 accepted Sept. 15, 2010

Bibliography Dol http://dx.doi.org/ 10.1055/s-0030-1250411 Published online October 13, 2010

Planta Med 2011; 77: 586-597

(c) Georg Thieme Verlag KG Stuttgart · New York . ISSN 0032-0943

\section{Correspondence}

Dr. Véronique Hannaert Research Unit

for Tropical Diseases de Duve Institute and Laboratory of Biochemistry

Université catholique de Louvain

Avenue Hippocrate 74

1200 Brussels

Belgium

Phone: + 3227647472

Fax: + 3227626853

veronique.hannaert

@uclouvain.be to humans by the bite of tsetse flies of the genus Glossina infected with trypanosomes. The parasites concerned are flagellated Protista belonging to the order Kinetoplastida and the family Trypanosomatidae. Two subspecies of Trypanosoma brucei are the causative agents of HAT: T. brucei gambiense endemic in western and central Africa, responsible for more than $90 \%$ of the reported cases of sleeping sickness and $T$. brucei rhodesiense in eastern and southern Africa, representing less than $10 \%$ of the cases [1]. The occurrence of HAT is restricted to the distribution of tsetse flies which are exclusively found in sub-Saharan Africa; more than 250 discrete active foci in 36 African countries are recognized, most of which are in rural areas ( Fig. 1) [2]. Within this area, sleeping sickness threatens over 60 million people. Less than $10 \%$ of the at-risk population is currently under surveillance.

Three major epidemics have ravaged the continent in the past century [3]. The first one, which being said, African trypanosomes continue to be among the most extensively studied parasitic protists to date. Many of their intriguing biological features have been well documented and can be viewed as attractive targets for antitrypanosomal chemotherapy. A considerable number of natural products with diverse molecular structures have revealed antiparasitic potency in the laboratory and represent interesting lead compounds for the development of new and urgently needed antiparasitics. The major validated drug targets in T. brucei are discussed with particular emphasis on those known to be attacked by natural compounds. 


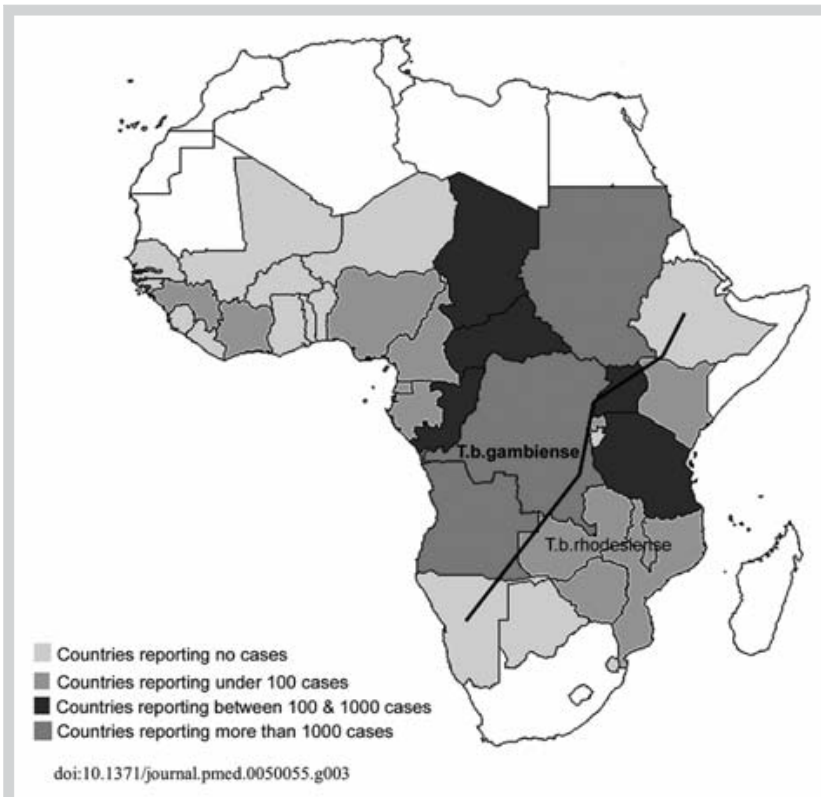

Fig. 1 A map of countries with HAT infections. The chronic form of the disease (T.b. gambiense) which is more widespread occurs west of the line, while the acute form (T.b. rhodesiense) is found to the east.

ducing the number of cases of HAT from 300000-500000 to approximately 50000-70000, along with 17000 new cases occurring annually [1].

T. brucei undergoes a life cycle in which it alternates between a mammalian host and the tsetse fly ( $\bullet$ Fig. 2) [5]. Metacyclic trypanosomes are transmitted to humans by the bite of an infected tsetse fly. Both male and female flies are blood-feeders and can thus bring about transmission. Within the mammalian host, the bloodstream forms show a polymorphism with dividing slender forms which transform via an intermediate form into nonproliferating stumpy forms. These latter are preadapted to survive within a tsetse fly. During a blood meal on an infected host, the fly ingests bloodstream-form trypanosomes which enter the digestive tract. Long-slender bloodstream forms do not survive while the short-stumpy trypanosomes differentiate into procyclic forms. During the following 3-5 weeks the trypanosomes undergo several differentiation steps from dividing procyclics to epimastigote forms, which migrate to the salivary glands, where they develop into the human/mammalian-infective metacyclic forms.

In the infected human, the disease develops from an early stage, where the parasites are mainly confined to the blood and lymph system, characterised by nonspecific symptoms, including fever, headaches, joint pains and itching, into a later stage, where more and more parasites manage to invade internal organs and also cross the blood-brain barrier to establish a cerebral infection. At the second stage, the patient suffers from torture of the central nerve system. Severe headaches, changes in mood and in the sleep cycle, mental disorientation and neurological disorders are the outcome [1]. Sleep disorder is a leading symptom of the second stage and is the one that gave the disease its name. If left untreated, sleeping sickness patients fall into a coma and succumb, often by developing secondary bacterial infections due to immunosuppression associated with sleeping sickness. The timed development of symptoms and the life expectancy strongly depend

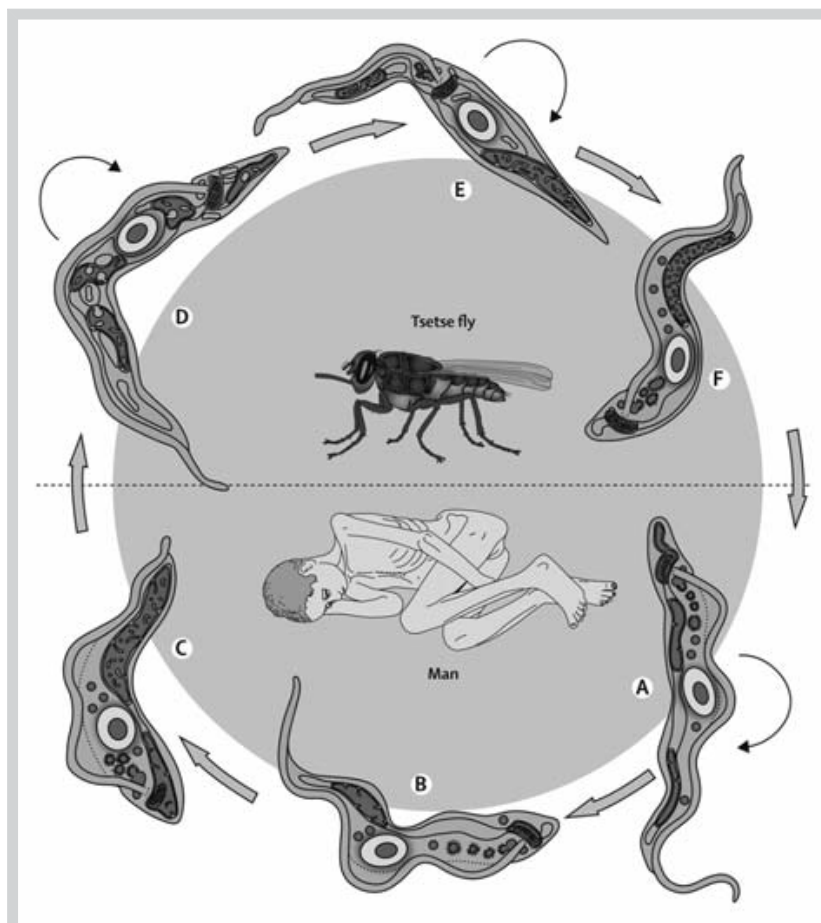

Fig. 2 The life cycle of Trypanosoma brucei. Parasites are transmitted to man by the bite of an infected tsetse fly. In man, the dividing bloodstream slender forms (a) transform via intermediate forms (b) into nondividing stumpy forms. In the tsetse fly, the stumpy forms (c) transform into procyclic forms (d) that proliferate in the midgut, then to the migrating epimastigote forms (e), which develop in the salivary gland to the infective metacyclic forms (f).

on the T. brucei subspecies. Infections with T.b. rhodesiense lead to an acute form of the disease, rapid in onset and that may last only a few weeks or months, while infections with T.b. gambiense give rise to a chronic infection slow in onset and its course may last from a few months to several years.

\section{Current Chemotherapy and Drug Resistance in HAT $\nabla$}

Few drugs are available to treat HAT and selection is based mainly on the development stage of the disease and the subspecies concerned [6,7]. Pentamidine is a water-soluble aromatic diamidine discovered in 1937 ( $\mathrm{OFig}$. 3). It is the first drug of choice for treatment of the early-stage disease caused by T.b. gambiense. Pentamidine is generally well tolerated. When given by intramuscular injection, site pain and transient swelling, abdominal pain and gastrointestinal problems and hypoglycaemia are the most frequently reported adverse events. Its usage may, however, be restricted due to cardiac dysrhythmias and hypotension or acute deterioration of bone marrow, renal or pancreatic function in immunodeficient patients or induction of abortion when used in pregnany. Many studies have focused on the mechanism of action of pentamidine; however, none appears to conclusively define the target [8]. Diamidine compounds belong to a class of DNA minor groove binders. Complex formation of diamidines with DNA may induce selective inhibition of DNA-dependent enzymes and/or may act through direct inhibition of transcription. In Leishmania (another genus of parasites belonging to the Trypanosomatidae family), fluorescent analogues of pentamidine ac- 
<smiles>N=C(N)c1ccc(OCCCCCOc2ccc(C(=N)N)cc2)cc1</smiles>

(a)
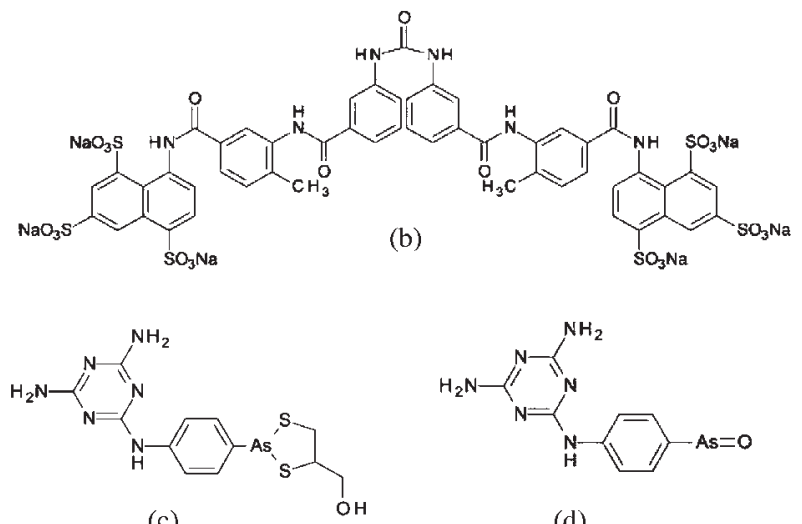

(c)

(d)<smiles>NCCCC(N)(F)C(=O)O</smiles>

(e)

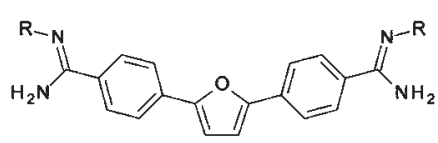

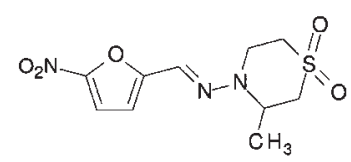

(f)
DB75 $\mathrm{R}=\mathrm{H}$

DB289 $\mathrm{R}=\mathrm{OCH}_{3}$

(g)

Fig. 3 Chemical structures of pentamidine (a), suramin (b), melarsoprol (c), melarsen oxide (d), eflornithine (e), nifurtimox (f), DB289 and DB75 (g).

cumulate selectively in the unique intercatenated network of circular DNA molecules termed the kinetoplast DNA, which make up the mitochondrial genome of all kinetoplastids. This location of the drug in the kinetoplast may be related to the higher adenine and thymine base pair content as compared to nuclear DNA. However, a dyskinetoplast strain (without kinetoplast DNA) of bloodstream-form T. brucei can persist in the bloodstream of mammals. Whether the localization correlates with activity is thus not confirmed.

Suramin, a sulphonated naphthylamine discovered in 1916, is used against early-stage sleeping sickness caused by T.b. rhodesiense ( Fig. 3). It provokes certain undesirable effects in the urinary tract as well as allergic reactions. Many hypotheses have been proposed for suramin's mode of action, but none proven. All glycolytic enzymes have been shown to be inhibited by suramin, as well as 6-phosphogluconate dehydrogenase, an enzyme of the pentose-phosphate pathway, thymidine kinase and dihydrofolate reductase. But, with six negative charges, the drug binds, by electrostatic interaction, to positively charged areas of many enzymes, and may thus exert its trypanocidal action through multiple targets.

Melarsoprol, an arsenical-base drug developed by Friedheim, was introduced in 1949 for treatment of sleeping sickness (๑ Fig. 3). Until 1990, it was the only agent available for treatment of latestage disease, both of eastern and western African origin. It is still the only effective drug for chemotherapy of second-stage T.b. rhodesiense sleeping sickness. Toxicity is an important concern with melarsoprol. The most important reaction is an encephalopathic syndrome that occurs in, on average, $4.7 \%$ of T.b. gambiense and $8.0 \%$ of T.b. rhodesiense patients, with a case fatality rate of $44 \%$ and $57 \%$, respectively [7]. Cardiotoxicity and exfoliative dermatitis are other severe and potentially life-threatening side effects. Treatment courses are long and uniformly require hospitalisation. In addition, melarsoprol-resistant parasites are well described from an increasing number of countries. In several foci, treatment failures have reached $30 \%$ of those treated. Although the mechanism of action of melarsoprol has been extensively studied, it remains unclear. Melarsoprol is not stable in plasma and is rapidly metabolised to melarsen oxide ( $\odot$ Fig. 3 ) [9]. It has been proposed that trivalent arsenicals with two replaceable ligands have a high affinity for intracellular thiol and other sulfhydryl-containing agents in the cell, including dihydrolipoate and the closely adjacent cysteine residues of many proteins. Other studies showed an inhibition of several enzymes like trypanothione reductase, 6-phosphogluconate dehydrogenase, pyruvate kinase, phosphofructokinase and fructose 2,6-bisphosphatase. Whether these interactions underlie the rapid lysis observed when trypanosomes are exposed to melarsoprol is not known.

Eflornithine ( $\alpha$-difluoromethylornithine, DFMO, Fig. 3), approved in 1990, is the only new molecule for treatment of HAT that has been registered in the past 60 years. It was initially developed as an anticancer agent by Merrell-Dow in the late 1970s, but was also found to be effective against late-stage T.b. gambiense sleeping sickness in patients that were refractory to melarsoprol treatment. Eflornithine is a rationally designed enzymeactivated, irreversible inhibitor of ornithine decarboxylase (ODC), the initial enzyme in the polyamine synthetic pathway ( Fig. 5) [10]. Inhibition of ODC results in the depletion of the polyamines putrescine and spermidine and also causes a loss of the unique antioxidant metabolite, trypanothione. It blocks cell division and thus depends on a functional immune system to rid the host of nondividing forms. The more rapid turnover rate of mammalian and T.b. rhodesiense ODC however, makes eflornithine ineffective as an anticancer drug and allows T. b. rhodesiense parasites to survive under conditions where T.b. gambiense, with a longer ODC half-life, cannot continue to proliferate. The major drawback with respect to eflornithine is the strict and difficult to apply regimen. Treatment lasts for two weeks, and because of the short plasma half-life of the drug, four short injections per day are necessary. The most frequent toxic reaction is bone marrow suppression leading to anaemia, leucopenia and thrombocytopenia (25-50\%) and gastrointestinal symptoms (10-39\%).

Very recently (2009), NECT (nifurtimox-eflornithine combination therapy) has been made available to patients for treatment of late-stage T.b. gambiense sleeping sickness. NECT consists of a simplified coadministration of oral nifurtimox and intravenous eflornithine [11]. Nifurtimox, a nitrofuran derivative, was developed in the 1960s by the Bayer Company ( $\odot$ Fig. 3). Its trypanocidal activity was empirically discovered and since 1967 it has been used for the treatment of Chagas' disease caused by Trypanosoma cruzi in Latin America. NECT represents an improved alternative over the current treatment for late-stage HAT: it is less toxic and more efficacious than melarsoprol, and cheaper and easier to administer than eflornithine monotherapy: only two infusions a day are required during 10 days. The biological basis for this therapy most likely lies in the ability of eflornithine to reduce trypanothione levels and resistance to oxidative stress 
and the ability of nifurtimox to generate reactive oxygen species in trypanosomes, although the mode of action of nifurtimox is not clearly known.

In recent years, one new compound, pafuramidine maleate (DB289) ( Fig. 3), a synthetic analogue of pentamidine, has received serious clinical evaluation against HAT. This diamidoxime prodrug is orally absorbed and then converted into the active diamidine furamidine (DB75) ( Fig.3) in the bloodstream. The prodrug showed good efficacy in patients with first-stage T.b. rhodesiense infection and progressed to phase III trials. Unfortunately, in February 2008, development was discontinued due to renal toxicity [12]. The non-profit Drugs for Neglected Diseases initiative (DNDi) in collaboration with Sanofi-Aventis is currently recruiting participants for the phase I clinical development of fexinidazole (5-nitroimidazole). In animal models of both T.b. gambiense and T.b. rhodesiense infections, fexinidazole shows highly promising efficacy. It is orally active and passes the blood-brain barrier, which means that it could be effective against both stages of sleeping sickness [13].

The current antitrypanosomal therapies are far from ideal. Besides the sometimes severe toxicity problems, the drugs have other drawbacks. Presently, they are all administered intramuscularly (pentamidine) or intravenously (suramin, melarsoprol and eflornithine), which makes the treatment impossible in areas where no medical facilities exist. The supply of these drugs has not always been guaranteed as drug companies periodically abandon production because of lack of profitability. At the moment, Sanofi-Aventis and Bayer, which currently produce all of the licensed anti-HAT drugs, donate them free of charge to the WHO which distributes them in Africa. The situation is further aggravated by the alarming incidence of treatment failures in several sleeping sickness foci, especially with melarsoprol, indicating the occurrence of drug-resistant trypanosomes. Most parasites selected for resistance to melarsoprol in the laboratory and several parasites isolated from relapsed cases in the field have lost the P2 aminopurine transporter. Pentamidine and melarsoprol are mostly internalised through this transporter, primarily responsible for the transport of adenosine and adenine, encoded by the tbat1 ( $T$. brucei adenosine transporter 1) gene. Pentamidine can also be internalised by the high-affinity pentamidine transporter 1 (HAPT1) and the low-affinity pentamidine transporter 1 (LAPT1). Surprisingly, trypanosomes from which the tbat1 gene has been removed are only marginally less sensitive to melarsoprol than the wild-type cells. High levels of melarsoprol resistance were observed when both transporters, P2 and HAPT1, were lost [14]. Another drug resistance mechanism for melarsoprol involves the overexpression of the efflux pump TbMRAP, localised in the plasma membrane of the parasites [15]. It belongs to the subfamily of multidrug resistance-associated proteins (MRPs) characterised by the need of ATP and thiols to transport molecules against a concentration gradient. Evidence for resistance to suramin and pentamidine from the field is rare and not considered as a problem in the treatment of sleeping sickness today. Treatment failures are believed to be largely due to misdiagnosed late-stage infections for which both drugs are not effective [16]. This lack of resistance is remarkable, as the drugs have been in use for more than 70 years and induction of resistant strains in the laboratory appears straightforward. No other drugs are available to treat the late-stage T.b. rhodesiense trypanosomiasis if strains were to develop resistance to melarsoprol. Added to the unacceptable side effect of encephalopathy, it shows the urgent need for new trypanocidal agents.
The prospects to develop a vaccine against the parasites are poor [17]. The human immune system cannot eradicate $T$. brucei because the parasite has developed an apparently insurmountable capacity for antigenic variation. The surface of the trypanosome is covered by a variant surface glycoprotein (VSG) that is the main antigenic determinant to the human immune system. The genome contains an estimated 1000 genes capable of coding for VSGs. One VSG gene is expressed at the time, but in a trypanosome population switching to the expression of a different VSG gene occurs semi-randomly at each generation at a relatively high frequency. Thereby, the antibodies generated no longer recognise the surface antigen of the parasite and its progeny with a new VSG coat, enabling the parasite always to be one step ahead of the host's immune defence mechanisms. This immune evasion mechanism makes it unlikely that a vaccine could be developed for HAT.

Vector control can block transmission and was successfully employed in the 1990s to eradicate trypanosomiasis from Zanzibar [18]. This was achieved by using extensive trapping, by the deployment of insecticide impregnated screens in some of the forested areas, followed by sequential releases of gamma-irradiation sterilized male flies twice a week along specific flight lines separated by a distance of $1-2 \mathrm{~km}$ during 30 months. Although very efficient, the implementation of such tsetse control measures in a coordinated fashion on the African continent has been proven very difficult.

This shows the strong need for research for new molecules against sleeping sickness which are safe, effective against both forms of the disease, at both disease stages, that do not require any particular skill or care to administer and are affordable.

\section{Natural Products as a Source of New Drugs against HAT}

$\nabla$

Nature is a potential source of such new drugs since it contains a countless quantity of molecules with a great variety of structures and pharmacological activities. The potential of natural products in the treatment of diseases can be seen in traditional medicines. For thousands of years, natural products have played an important role throughout the world in treating and preventing human diseases. The first records, written on clays tablets in cuneiform, are from Mesopotamia and date from about 2600 BC [19]. The WHO estimates that two thirds of the world's inhabitants continue to rely mainly on traditional medicine systems for their health care. Natural product medicines have come from many types of organisms ranging from bacteria, fungi and plants to protists, sponges and other invertebrates found in diverse environments such as deep seas, rain forests and hot springs. In an extensive review of new drugs introduced between 1981 and 2006, 28\% of the 1184 new chemical entities were natural products or derived from natural products, with another $24 \%$ created around a pharmacophore from a natural product [20].

Several well-established human antiprotist drugs have their origins in nature, such as quinine and artemisinin used to treat malaria. The isolation of quinine from the bark of Cinchona species was reported in 1820 by the French pharmacists, Caventou and Pelletier. The bark had long been used by indigenous groups in the Amazon region for the treatment of fevers, and was first introduced into Europe in the early 1600s for the treatment of malaria [19]. In the early days, quinine was the curative agent for malaria and subsequently synthetic derivatives (chloroquine, amodiaquine, primaquine and mefloquine) have been developed. 
Despite its long history of use as a plant preparation or as a pure compound, quinine is still an important drug for treatment of malaria, in particular cerebral malaria. The discovery in 1969 of the antimalarial properties in extracts of Artemisia annua, another plant long used in treatment of fevers in Chinese traditional medicine, and the subsequent isolation of artemisinin one year later by Zhenxing Wei, a Professor of Traditional Medicine at the Research Institute of Shandong (China), represented one of the major breakthroughs of the past decades in the fight against parasitic diseases. Currently, several semisynthetic derivatives of artemisinin have been registered (artemether, artesunate and dihydroartemisinin). Artemisinin derivatives are the only antimalarial drugs for which no resistance of Plasmodium strains has so far been characterised in the field and are considered as the most effective drugs against malaria [21]. However, unmistakable signs of malaria parasites becoming resistant to artemisinin have very recently been reported from the border region between Thailand and Cambodia [22].

In Africa, plants have been used traditionally for centuries and are still widely employed to treat sleeping sickness [23]. However, little is known about the treatment of HAT with plant-derived drugs $[24,25]$ and no trypanocidal drug molecule from natural origin is currently used against $T$. brucei infections. Although the literature contains relatively few studies reporting the activity of natural products on HAT compared to other diseases caused by protists such as malaria, or even leishmaniasis and Chagas' disease caused by other trypanosomatid parasites, the variety of compounds isolated from natural sources with anti-T. brucei activities is wide. This is illustrated in several recent reviews [21, 26-29]. Several compounds isolated from a natural source have been shown to inhibit the growth of trypanosomes in vitro with $\mathrm{EC}_{50}$ values in the submicromolar range and for some of these products this activity seems to be quite selective. However, only a few of them have been evaluated for in vivo activity in infected animal models and none of them have proceeded to clinical studies or are projected to reach clinical application in the near future.

\section{Compounds Screening against T. brucei}

$\nabla$

The data in the literature are often difficult to compare due to the different assay procedures used in the various laboratories. The reliability of the results may also be a major problem: there are many examples of poorly conducted trials with inadequate controls, often involving no measure of cytotoxicity and no positive control compound. Without measure of selective toxicity against the parasite, there is a high probability that many of the products that have been classified as "active" against $T$. brucei in vitro are likely to be general toxins, and quite unsuitable for development as an antiparasitic product.

As far as possible, new molecules should be evaluated in defined, controlled and validated assays as an essential first step to determine if real intrinsic activity exists. Such a defined system is important to compare compounds from different studies, to compare them with known active drugs and to evaluate the level of toxicity for the host. This should enable rational decisions to be made on the potential of a new compound for further development. A manual with standardised drug screening methodologies for kinetoplastid-caused diseases (HAT and leishmaniasis) has been produced by the Pan-Asian Network for Drugs for Neglected Diseases (PAN4ND) in April 2009. The PAN4ND serves to encourage research collaboration between member institutions from across the world (primarily in Asia) to maximise the potential for drug development from natural products for neglected diseases. This network is coordinated by the Drugs for Neglected Diseases Initiative (DNDi), a not-for-profit drug research and development organisation founded in 2003, that is developing new treatments for malaria, visceral leishmaniasis, sleeping sickness and Chagas' disease in partnership with industry, academia and NGOs. This guide provides recommendations and detailed protocols for screening natural products in vitro (cultured whole cells) and in vivo (in animals) against pathogens responsible for sleeping sickness and leishmanaisis, but also the principles of good practice related to the preparation, realisation and processing of these assays and the data. An electronic version is available at the following URL: www.pan4nd.org. Screening natural products provides the chance to discover new molecules of unique structure with high activity and selectivity which can be further optimised by semisynthetic or fully synthetic procedures. It is important that methodologies and protocols of screening assays are harmonised to enable comparison of results obtained in different laboratories and facilitating collaboration and understanding among groups.

Following an initiative by the WHO/TDR in 2000, there is now the opportunity for scientists from academia and industry to evaluate free of charge their compounds in validated antiparasite and toxicity tests in screening centres [30]. Two centres are dedicated to screens for African trypanosomiasis: the Swiss Tropical Institute (STI) in Basel (Switzerland), which provides in vitro and in vivo tests and the Laboratory for Microbiology, Parasitology and Hygiene at the University of Antwerp (LMPH) (Belgium), which provides in vitro screens.

\section{Target Determination}

$\nabla$

Most studies on antitrypanosomal activities of natural products have been focused on testing the compounds for their ability to inhibit parasite growth in vitro or in vivo rather than on the optimisation of existing lead natural products. Moreover, even when a natural product is found to exhibit biological activity, its cellular target and mode of action are almost never thoroughly studied; very often, only possible mechanisms are suggested.

However, T. brucei is a popular organism for biological research. It can easily be grown in culture and laboratory animals. Its biology and biochemistry have been extensively studied since it represents a branch of organisms that evolved separately from other branches - including the one comprising the well-studied vertebrates and fungi - derived from the last common ancestor of the eukaryotes and exhibits a large number of unusual features. This has led to the identification of a variety of putative drug targets that are unique to the parasite or that differ significantly from those present in its mammalian host. In 2005, its genome sequence was published, allowing comparative analyses to be carried out in a direct mode, towards a better understanding of biological, genetic and evolutionary aspects [31]. Such analyses make possible the identification of gene products related to pathogenesis, as well as proteins involved in crucial metabolic pathways that may lead to drug discovery and development. Moreover, $T$. brucei is amenable to drug target validation through genetic means $[32,33]$. One such technique is RNA interference (RNAi), a method in which expression of a double-stranded RNA (dsRNA) in trypanosomes causes selective degradation of the 
cognate mRNA. RNAi has proven to be a powerful experimental tool to address the biological function of proteins [34]. This technique has, however, some weaknesses: it is often difficult to rule out "off-target" effects attributed to unintentional silencing, target knock-down by RNAi does not permit independent analysis of bifunctional enzymes and insufficient expression of dsRNA might fail to knock down target expression to the levels required for revealing a phenotype [35].

For several natural products, the targets in $T$. brucei have been formally identified. Often, these targets appeared to be enzymes involved in important metabolic processes which are sufficiently different from corresponding proteins in the mammalian host or they are absent in the host - to avoid a too high toxicity. The various examples will be discussed in the next section of this review.

\section{Carbohydrate metabolism and alternative oxidase}

Energy metabolism, notably glycolysis, is considered to be a good drug target in $T$. brucei because, when living in the bloodstream of its mammalian host, the parasite is entirely dependent on the conversion of glucose, present in the blood and body fluids, into pyruvate for its ATP supply. Moreover, trypanosomatid glycolysis is unique in that it is compartmentalised, and many of its enzymes display unique structural and kinetic features [36]. The seven glycolytic enzymes converting glucose into 3-phosphoglycerate are localised within specialised peroxisome-like organelles called glycosomes, in contrast to the situation in other organisms where the glycolytic enzymes are cytosolic ( $\odot$ Fig. 4). The last three enzymes of the pathway are present in the cytosol. Most of the glycolytic enzymes have been validated by RNAi as good drug targets $[37,38]$. Even their partial depletion leading to the reduction of the glycolytic flux to approximately $50 \%$ of wildtype levels is already sufficient to kill trypanosomes in culture.

The glycosomal NADH produced from the reaction catalysed by glyceraldehyde 3-phosphate dehydrogenase is re-oxidised inside the organelle followed by the transfer of the electrons to $\mathrm{O}_{2}$ via a mitochondrial glycerol 3-phosphate oxidase (GPO). This process involves a glycosomal NADH-dependent glycerol 3-phosphate dehydrogenase, a putative transporter in the glycosomal membrane that exchanges glycerol 3-phosphate for dihydroxyacetone phosphate, and the mitochondrial GPO. The GPO is a system comprising an FAD-linked glycerol 3-phosphate dehydrogenase, ubiquinone and a terminal oxidase, known as the trypanosome alternative oxidase (TAO) present in the inner mitochondrial membrane. Because, in mammalian cells, TAO does not occur, this essential re-oxidation system of $T$. brucei has attracted attention as a target for trypanocidals. When TAO is inhibited by salicylhydroxamic acid (SHAM), the glycerol 3-phosphate is then converted into glycerol via the reverse action of a glycosomal glycerol kinase thermodynamically unfavourable and only feasible by mass action at high glycerol 3-phosphate concentration and a high ADP/ATP ratio. It has been demonstrated that, in combination with glycerol which suppresses the glycerol-producing pathway, inhibitors of the TAO become trypanocidal due to a total block of the energy production of bloodstream forms [39].

Two natural compounds have been demonstrated to inhibit specifically the TAO: ascofuranone, a prenylated phenol antibiotic produced by the phytopathogenic fungus Ascochyta visiae and azaanthraquinone isolated from the leaf of Mitracarpus scaber. They are potently trypanocidal in vitro for bloodstream forms only when combined with glycerol. Azaanthraquinone kills $50 \%$ of the parasites within $10 \mathrm{~min}$ at $250 \mu \mathrm{M}$, but the $\mathrm{EC}_{50}$ is reduced

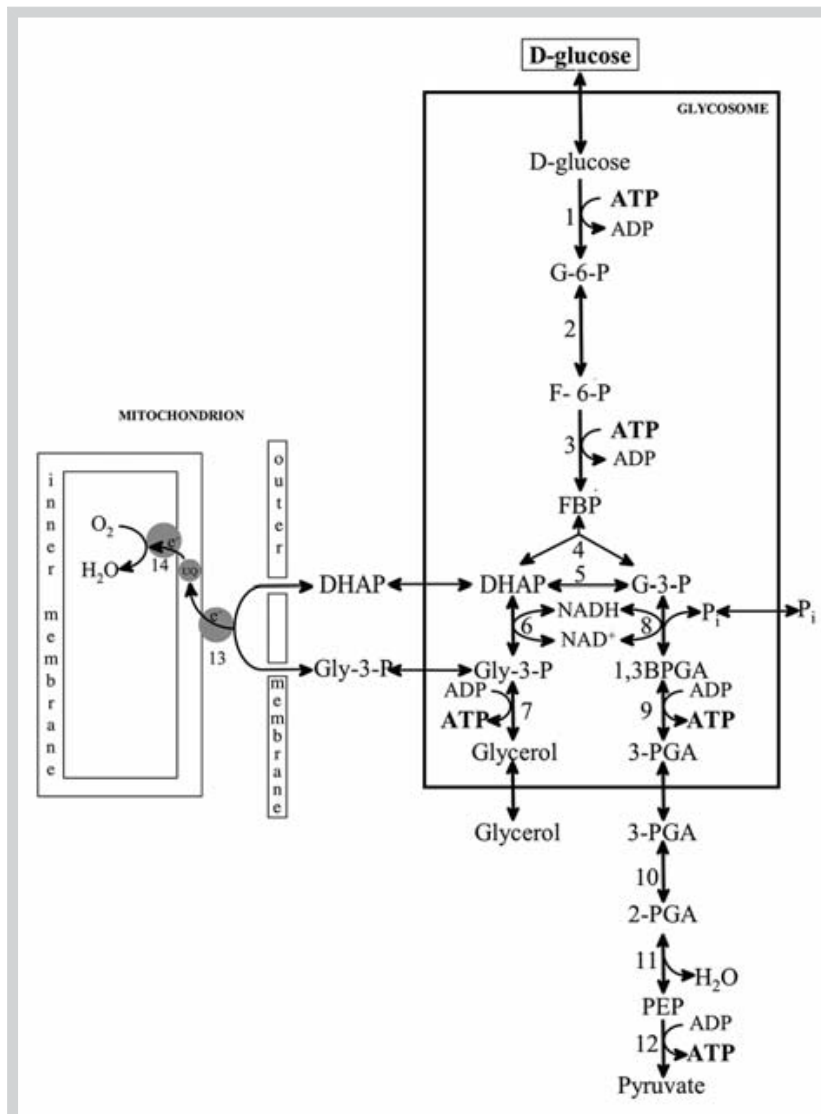

Fig. 4 Schematic representation of glycolysis in the bloodstream-form of T. brucei. Under aerobic conditions, glucose is converted into pyruvate. Under anaerobic conditions equimolar amounts of glycerol and pyruvate are produced. Abbreviations: 1,3BPGA, 1,3-bisphosphoglycerate; DHAP, dihydroxyacetone phosphate; F-6-P, fructose 6-phosphate; FBP, fructose 1,6bisphosphate; G-3-P, glyceraldehyde 3-phosphate; G-6-P, glucose 6-phosphate; Gly-3-P, glycerol 3-phosphate; PEP, phosphoenolpyruvate; 3-PGA, 3-phosphoglycerate; Pi, inorganic phosphate; UQ, ubiquinone pool. Enzymes are: 1 , hexokinase; 2 , glucose-6-phosphate isomerase; 3 , phosphofructokinase; 4 , aldolase; 5 , triosephosphate isomerase; 6 , glycerol-3-phosphate dehydrogenase; 7, glycerol kinase; 8, glyceraldehyde-3-phosphate dehydrogenase; 9, glycosomal phosphoglycerate kinase; 10, phosphoglycerate mutase; 11 , enolase; 12 , pyruvate kinase; 13 , FAD-dependent glycerol-3-phosphate dehydrogenase; 14 , alternative oxidase.

to $25 \mu \mathrm{M}$ in the presence of $4 \mathrm{mM}$ glycerol [40]. This result and the observation of an immediate cessation of flagellum movement after incubation with azaanthraquinone allowed the authors to conclude that the TAO was the target. For ascofuranone, the $\mathrm{EC}_{100}$ is $250 \mu \mathrm{M}$ in the absence of glycerol and $0.03 \mu \mathrm{M}$ in the presence of $4 \mathrm{mM}$ glycerol [41]. This latter compound was able to cure mice from an infection with $T$. brucei when administered in combination with glycerol or alone if higher doses and a longer treatment were applied $[42,43]$. The inhibition of the respiratory chain by ascofuranone, a host-mediated antitumour agent, had already been demonstrated in eukaryotic cells [44].

Tubercidin is an adenosine analogue isolated from the bacterium Streptomyces tubercidicus with antibiotic and potential antineoplastic activity. It is also known to kill trypanosomatid parasites with an $\mathrm{EC}_{50}$ of $0.84 \mu \mathrm{M}$. In mammalian cells, it is the substrate of adenosine kinase and is incorporated into DNA and RNA, thereby inhibiting their replication. An RNAi library was used to study the mechanism of toxicity of this compound to procyclic (insect 
stage) T. brucei [45]. In the drug-resistant cell lines isolated, it was found that the hexose transporters had been silenced. The link between tubercidin and glucose metabolism was further confirmed when it was shown that depletion of hexokinase by RNAi or adaptation to grow in a glucose-depleted medium conferred resistance to the compound and that the glycolytic intermediate, 1,3-bisphosphoglycerate, accumulated in parasites treated with tubercidin. In contrast to bloodstream form trypanosomes, procyclic forms can utilise several pathways, including glycolysis for energy supply and therefore cells not capable of glycolysis are resistant to tubercidin. Such a possibility for developing resistance may thus be excluded for bloodstream form trypanosomes.

Polycarpol isolated from Piptostigma preussi exhibits antitrypanosomal activity with an $\mathrm{EC}_{50}$ value of $5.11 \mu \mathrm{M}$ on $T$. brucei cells. It appeared to be a potential inhibitor of the $T$. brucei glycolytic enzyme phosphofructokinase with an $\mathrm{EC}_{50}$ value of $180 \mu \mathrm{M}$ [46].

\section{Thiol metabolism}

During their life cycle, $T$. brucei cells are exposed to various reactive oxygen intermediates, but they lack catalase and the classical selenium-containing glutathione peroxidases, two major hydroperoxide-eliminating enzymes generally found in other eukaryotes. Detoxification of hydroperoxides in trypanosomes is mediated by a series of linked redox pathways that are dependent on the parasite-specific thiol trypanothione for reducing equivalents (○ Fig. 5) [47]. This is unique because in nearly all organisms (including their mammalian host), maintenance of an intracellular reducing milieu is possible by means of high concentrations of glutathione (GSH). Trypanothione is a conjugate of two glutathione molecules with one spermidine. In T. brucei, as in other organisms, glutathione is synthesised by the consecutive activity of the enzymes $\alpha$-glutamylcysteine synthetase and glutathione synthetase. The polyamine spermidine is synthesised from ornithine and methionine via a ubiquitous pathway consisting of four enzymatic steps. The synthesis of trypanothione starts with the formation of glutathionylspermidine catalysed by glutathionylspermidine synthetase, followed by insertion of a second glutathione molecule catalysed by trypanothione synthetase. This dithiol is involved in a number of critical biological functions including deoxyribonucleotide synthesis, defence against oxidative stress, conjugation and export of metals and drugs [48]. These cellular processes consume reducing equivalents derived from dihydrotrypanothione $\left[\mathrm{T}(\mathrm{SH})_{2}\right]$, the reduced form of trypanothione, and produce trypanothione disulphide $\left(\mathrm{TS}_{2}\right)$ which is recycled back to $\mathrm{T}(\mathrm{SH})_{2}$ by trypanothione reductase, an NADPH-dependent disulphide oxidoreductase. Although $\mathrm{T}(\mathrm{SH})_{2}$ is a potent direct reducing agent, enzymatic pathways link $\mathrm{T}(\mathrm{SH})_{2}$ to hydroperoxide reduction in order to accelerate many reactions [49]. They consist in the concerted action of two proteins, a tryparedoxin and a tryparedoxin peroxidase. Tryparedoxins are trypanothione-dependent oxidoreductases reduced by $\mathrm{T}(\mathrm{SH})_{2}$. Depending on their subcellular compartmentalisation, tryparedoxins react with different tryparedoxin peroxidases. Two major families of peroxidases have been identified in T. brucei: 2-cysteine peroxiredoxin peroxidases present in the cytosol and mitochondrion and nonselenium glutathione peroxidases found in the cytosol, in the mitochondrion and in the glycosomes.

Trypanothione participation in numerous physiological pathways renders this thiol crucial for $T$. brucei survival and its absence from the mammalian host metabolism makes it an attractive drug target. This has been unequivocally demonstrated using genetic techniques such as classical gene knockout and RNAi. Try-

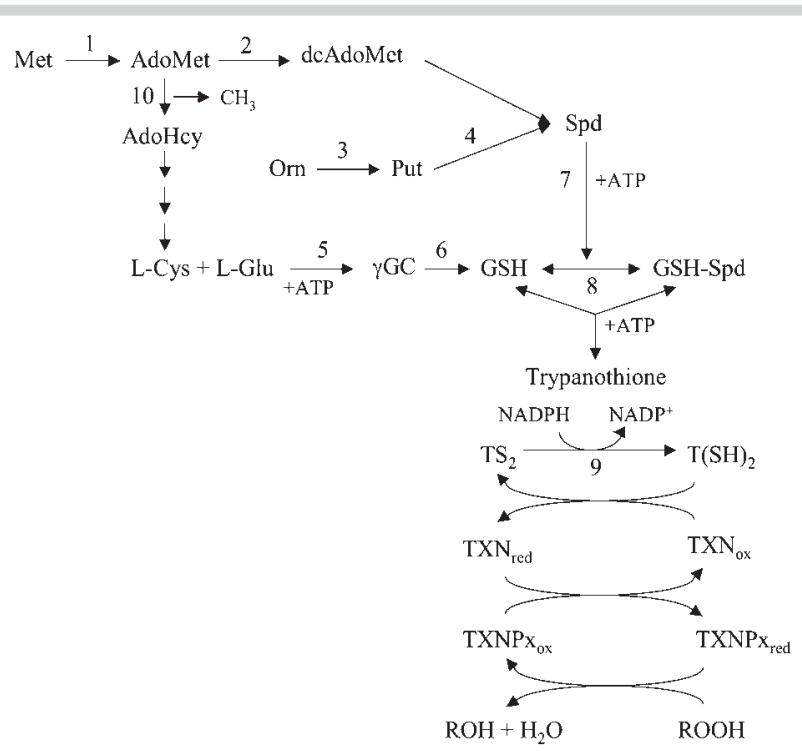

Fig. 5 Schematic representation of thiol metabolism in T. brucei. Abbreviations: Met, methionine; AdoMet, adenosylmethionine; Orn, L-ornithine; Put, putrescine; Spd, spermidine; t-Cys, t-cysteine; t-Glu, t-glutamine; $\gamma \mathrm{GC}$, $\gamma$-glutamylcysteine; $\mathrm{GSH}$, glutathione; GSH-Spd, glutathionylspermidine; $\mathrm{TS}_{2}$, oxidized trypanothione; $\mathrm{T}(\mathrm{SH})_{2}$, reduced trypanothione; $\mathrm{TXN}_{\text {red, }}$, reduced tryparedoxin; $\mathrm{TXN}_{\mathrm{ox}}$, oxidized tryparedoxin; $\mathrm{TXNPx}_{\text {red }}$, reduced tryparedoxin peroxidases; TXNPx ox, oxidized tryparedoxin peroxidases; AdoHcy, S-adenosylhomocysteine. Enzymes are: 1, S-adenosylmethionine synthetase; 2, S-adenosylmethionine decarboxylase; 3 , ornithine decarboxylase; 4 , spermidine synthetase; $5, \gamma$-glutamylcysteine synthetase; 6 , glutathione synthetase; 7 , glutathionylspermidine synthetase; 8 , trypanothione synthetase; 9 , trypanothione reductase; 10 , transmethylase reactions.

panothione-dependent enzymes that have been validated as potential drug targets using these methodologies include $S$-adenosylmethionine decarboxylase [50], trypanothione synthetase [51], trypanothione reductase [52], tryparedoxin [53] and tryparedoxin peroxidases [53].

The polyamine biosynthetic pathway is the target of the only clinically proven antitrypanosomal drug with a known mechanism of action: eflornithine inhibits the biosynthesis of spermidine, a constituent of trypanothione [54]. Polyamines are generally essential for cell growth and even more in T. brucei because their biosynthetic pathway is uniquely linked to trypanothione biosynthesis.

The $S$-adenosylmethionine (AdoMet) analogue sinefungin is a natural product antibiotic isolated from cultures of Streptomyces incarnatus and S. griseolus that inhibits nucleic acid methyltransferases and arrests the growth of unicellular eukaryotes and viruses. This compound has been reported to display antiparasitic activity against Plasmodium, Trypanosoma and Leishmania species. Sinefungin blocks the in vitro growth of a drug-susceptible laboratory $T$. brucei strain with an $\mathrm{EC}_{50}$ of $0.4 \mathrm{nM}$ and a multiple drug-resistant strain from the field with an $\mathrm{EC}_{50}$ of $7 \mu \mathrm{M}$ with high selectivity [55]. The compound had no effect on mice infected with the drug-resistant strain but had the potential to cure mice when other strains where tested. Unfortunately, experiments have shown that sinefungin is severely nephrotoxic in goats [56]. When trypanosomes are incubated for $6 \mathrm{~h}$ with sinefungin, the intracellular concentration of AdoMet reaches nearly 20 times control levels because, contrary to the situation in mam- 
malian cells, the $S$-adenosylmethionine synthetase is not inhibitied by its product ( $\boldsymbol{O}$ Fig. $\mathbf{5}$ ). At this time, intracellular cysteine levels decreased by $70 \%$ due to transmethylation inhibition [57]. Gallic acid, a naturally abundant plant phenolic compound, and an ester derivative, $n$-propyl gallate, were reported to have trypanocidal activity against bloodstream forms of $T$. brucei $\left(\mathrm{EC}_{50}=\right.$ 15.6 and $1.5 \mu \mathrm{M}$, respectively) [58]. The superoxide anion $\left(\mathrm{O}_{2}{ }^{-}\right)$ generated during the autoxidation of gallic acid suggests that it might act as a pro-oxidant, while its ester derivative shows an increased activity in the presence of $4 \mathrm{mM}$ glycerol, suggesting an inhibition of respiration [59].

\section{Topoisomerases and kinetoplast DNA}

DNA topoisomerases are ubiquitous enzymes that catalyse topological changes in DNA molecules during replication, transcription, recombination and repair. They are classified into two types, based on the number of DNA strands cleaved: type I enzymes cleave one strand, while type II enzymes cleave both strands in reactions requiring ATP. On the basis of primary structure and reaction mechanism, type I topoisomerases are further subdivided into type IA and type IB [60]. T. brucei has at least six catalytically active topoisomerases located in the nucleus and the mitochondrion. These parasites have a single mitochondrion with a unique mitochondrial DNA, known as kinetoplast DNA (kDNA), a topologically complex network that contains thousands of interlocking circular DNAs, termed minicircles (each approximately $1 \mathrm{~kb}$ ) and 20-50 maxicircles (each approximately $23 \mathrm{~kb}$ ). Maxicircles encode ribosomal RNA and a handful of proteins, which are mostly subunits of respiratory complexes, but they cannot be translated until they are edited by the insertion or deletion of uridylates at specific internal sites. Small guide RNA templates, which are mostly encoded by minicircles, determine editing specificity [61]. The kinetoplast network is highly sensitive to drugs that intercalate into DNA or that interfere with kDNA replication.

T. brucei has three type IA topoisomerases, one of which, topoisomerase IAmt located exclusively in the mitochondrion, has no obvious orthologue in humans. When the expression of this enzyme is silenced by RNAi, there is a subsequent loss of kDNA networks and halt in cell growth [62]. The single topoisomerase IB of $T$. brucei is an enzyme singularly distinct from its mammalian counterpart. While all other described type IB topoisomerases are monomeric, the enzyme from kinetoplastids is heteromultimeric, composed of two distinct proteins encoded by two independent genes. RNAi studies have revealed that this enzyme is essential for T. brucei [63]. Two genes for type II topoisomerases in $T$. brucei have been identified. One enzyme localises to the nucleus and its depletion by RNAi leads to pleomorphic nuclear (but not kDNA) abnormalities and early growth arrest [64]. The second enzyme is located in the mitochondrion and RNAi silencing leads to a progressive loss of kDNA networks without a detectable effect on nuclear DNA [65].

DNA topoisomerase inhibitors represent a major group of anticancer drugs [66]. Some of these antitumour drugs also inhibit selectively trypanosomal topoisomerases. Camptothecin is a well-characterised inhibitor of DNA topoisomerase IB from eukaryotes and is selectively toxic for tumour cells. This pentacyclic alkaloid is produced in many plants belonging to unrelated orders of angiosperms, but is usually supplied for pharmaceutical use as an extract from Camptotheca acuminata and Nothapodytes foetida. When tested on T. brucei, it was shown to be cytotoxic with an $\mathrm{EC}_{50}$ value of $1.5 \mu \mathrm{M}$ and to form adducts with both kDNA and nuclear DNA, indicating action against nuclear and mitochondrial isoforms [67]. Camptothecin affected cell morphology (larger cells) and led to an increase in the relative numbers of G2 cells [68]. Diospyrin is similar to camptothecin with respect to inhibition of catalytic activity of DNA eukaryotic polymerase IB. This plant-derived compound inhibits the cell proliferation of $T$. brucei with an $\mathrm{EC}_{50}$ value of $50 \mu \mathrm{M}$ [69]. Three major aporphine alkaloids (actinodaphine, cassythine and dicentrine) isolated from Cassytha filiformis (Lauraceae), a plant often used in African folk medicine to treat cancer, HAT and other diseases, were active on $T$. brucei cultured in vitro $\left(\mathrm{EC}_{50}=3-15 \mu \mathrm{M}\right)$ [70]. The identification of dicentrine as a strong topoisomerase II catalytic inhibitor and a DNA intercalating agent in mammalian cells led the researchers to investigate the mechanism of action of these compounds. The results indicated that these molecules bind to DNA and also interfere with the catalytic activity of topoisomerases. Two anthracycline antibiotics, aclarubicin isolated from Streptomyces galilaeus and doxorubicin isolated from Streptomyces peucetius are topoisomerase inhibitors. These approved anticancer drugs exhibited antitrypanosomal activity with $\mathrm{EC}_{50}$ values of 3.3 and $27 \mathrm{nM}$, respectively [71]. Berberine, isolated from many Berberis spp. and sanguinarine, purified from many genera of the Papaveraceae, have shown in vitro activity against $T$. brucei ( $\mathrm{EC}_{50}$ of $0.53 \mu \mathrm{M}$ and $1.9 \mu \mathrm{M}$, respectively) [72]. They are both DNA intercalators [73,74].

\section{Farnesyltransferase}

Protein prenylation is an essential post-translational modification that occurs in most, if not all, eukaryotic cells [75]. Isoprenyl lipids covalently attached to proteins are either farnesyl (15-carbon) or geranylgeranyl (20-carbon) products of the mevalonate pathway. Depending on substrate specificity, the enzymes catalysing the attachment of the prenyl groups are designated as either farnesyltransferases (FT) or geranylgeranyltransferases I or II (GGTI, GGTII). This type of modification creates a hydrophobic tail that facilitates membrane association as well as protein-protein interactions. Prenylated proteins play a role in cell signal transduction, vesicle trafficking and cell cycle progression. Inhibitors of protein farnesyltransferase (PFT) have been developed as anticancer chemotherapeutic agents because the farnesylation of the ras oncogene product is required for its proper localisation and function. T. brucei PFT is, like the mammalian enzyme, a heterodimer but the subunits are larger due to numerous peptide segment insertions. The geranylgeranyltransferase type I seems to be absent in $T$. brucei, perhaps explaining the extreme sensitivity of these organisms to PFT inhibitors compared with mammalian cells. In mammalian cells, when PFT is inhibited, proteins that are normally farnesylated can be geranylgeranylated by PGGT-I [76].

Manumycin A, another antibiotic produced by Streptomyces, is a competitive inhibitor of mammalian FT showing antitumor activity. It inhibits growth of bloodstream form $T$. brucei in vitro with an $\mathrm{EC}_{50}$ of $1.5 \mu \mathrm{M}$, but is unable to cure trypanosomiasis in mice when given intraperitoneally. Manumycin specifically targets the farnesylation of proteins, but a swollen mitochondrion is also observed by immunofluorescence suggesting an additional site of action [77]. Because very little is known about the identities of prenylated proteins in T. brucei, the mechanism of FT inhibitors remains unclear. 


\section{Tubulin}

Tubulin is a heterodimeric protein consisting of $\alpha$ and $\beta$ subunits which polymerise to form microtubules. These microtubules have functions in important processes such as chromosome segregation, motility and maintenance of cellular morphology. Both shape and motility, provided by the single flagellum, play important roles in the complex life cycle of trypanosomes. Tubulin is an established target in the chemotherapy of many diseases, as drugs interacting with tubulin are available for treatment of cancer and helminth infections [78]. It has recently been demonstrated to be a possible target for antitrypanosomatid drug discovery [79].

Two natural products, colicin and vinblastine, are able to inhibit parasite growth in vitro [80]. Colicin is a type of bacteriocin produced by and toxic to some strains of Escherichia coli. Vinblastine is a Vinca alkaloid isolated from the Catharanthus (Madagascar periwinkle) plant used as a component in a number of chemotherapy regimens against cancers of white blood cells. The authors have shown that the inhibition of trypanosome growth was unequivocally due to the interaction of the molecules with tubulin.

\section{Validated drug targets whose inhibition \\ by natural products has not been reported as yet}

There are many other validated drug targets in $T$. brucei for which inhibition by natural products has not yet been described. Very recently, Frearson et al. [81] showed that protein $N$-myristoylation is an attractive target. This process refers to the covalent attachment of the fatty acid myristic acid to the N-terminal glycine of a small subset of cellular proteins. $\mathrm{N}$-Myristoylation often plays a role in targeting proteins to membrane locations and can additionally be involved in mediating protein-protein interactions and stabilising protein structure. In T. brucei, the enzyme myristoyl-CoA-protein N-myristoyltransferase (NMT) catalysing this reaction is encoded by a single gene which has been shown to be essential for parasite growth using RNAi. High affinity inhibitors of this target cause rapid killing of trypanosomes both in vitro and in vivo and cure trypanosomiasis in mice. The effects of NMT inhibition on $T$. brucei are probably complex as more than 60 proteins are predicted to be $\mathrm{N}$-myristoylated in this organism. The purine salvage pathway is a well-known target because, unlike its mammalian host, $T$. brucei lacks the pathways for de novo purine biosynthesis and relies on the salvage pathways to meet its purine demands [82]. Fatty acid synthesis occurs also in a unique way in $T$. brucei: it uses endoplasmic reticulum-associated elongases to synthesise fatty acids de novo, whereas other cells use elongases only to make long-chain fatty acids even longer [83]. Protein kinases, key mediators of growth and cell signalling, are one of the major drug target families being tackled by the pharmaceutical industry. The T. brucei genome encodes $176 \mathrm{pu}-$ tative protein kinases and several have been shown to be essential for proliferation and/or viability of parasites [84].

\section{Other targets}

It is almost impossible to cover all of the validated metabolic pathways or proteins currently investigated as possible antitrypanosomatid targets. Further information may be obtained on the TDR targets database (http://tdrtargets.org). It is an open access website where researchers can look for information of specific interest. The aim of this website is to capture, collate and make publicly available expert knowledge on potential drug tar- gets against parasitic diseases. In addition, it proposes a tool to exploit the availability of diverse datasets to facilitate the identification and prioritisation of drug targets in pathogens causing neglected diseases [85].

In the literature, reports of $T$. brucei growth inhibition assays can be found for a number of natural products with known specific action sites in other kinds of cells. This concerns particular compounds active on proteins playing a role in cell proliferation (e.g., macromolecular synthesis, energy metabolism) because rapidly dividing cells such as proliferative tumours, but also some parasites, tend to be selectively inhibited. Any trypanocidal activity for these compounds has been assumed to indicate that the specific targets were the same in trypanosomes. Very often, the mechanism of action has thus merely been suggested, only occasionally has it been investigated. There are very few examples in the literature where the mode of action of an inhibitor was experimentally determined. Kubata et al. [86] purified a proanthocyanidin from a Kola acuminata nut showing anti-T. brucei activity in vitro and in mice. By electron microscopy they observed ultrastructural alterations caused by rupture of plasma membranes and release of cell contents. Cordycepin, a metabolite from the fungus Cordyceps spp., was selected as the best candidate drug from a direct parasite viability screening of a 2200 nucleoside analogues library. It is used in combination with deoxycoformycin, an adenosine deaminase inhibitor that prevents the degradation of cordycepin in vivo, for the treatment of certain malignant tumours in humans [87]. The same coadministration of compounds was effective for treatment of late-stage experimental infections with T.b. rhodesiense and T.b. gambiense in mice. The mechanisms accounting for the trypanocidal effect were investigated. The authors found that codycepin induces progammed cell death of the parasites followed by secondary necrosis by measuring DNA degradation with propidium iodide and the translocation of phosphatidylserine from the inner to the outer leaflet of the plasma membrane [88]. The same observations were made for quercetin, one the most common polyphenolic flavonoids present in plants such as onions, Ginkgo biloba and tea. This compound kills T.b. gambiense by apoptosis with an $\mathrm{EC}_{50}$ of $10 \mathrm{mM}$ [89]. A chemical proteomics approach has also been applied to isolate and identify the cellular target of a compound. To this end, the inhibitor or derivatives have been immobilised on a column and these affinity matrices subsequently have been used to pull down potential targets. This methodology was used to identify the putative targets of 4-[5-(4-phenoxyphenyl)-2H-pyrazol-3-yl]morpholine (a synthetic inhibitor of T.b. rhodesiense growth) and cymelarsan (an arsenical drug used in the treatment of veterinary trypanosomiasis) $[90,91]$. Adenosine kinase and glycerol 3-phosphate dehydrogenase were found as the respective targets.

The understanding of the molecular mode of action should always be attempted because it may help to more easily develop derivatives with increased activity and/or lower toxicity. But it is clear that it cannot always be achieved and an inability to conclusively identify a target or demonstrate a mechanism of action should not necessarily terminate the development of an otherwise promising drug candidate. After all, all but one of the currently drugs for HAT were discovered via screening for activity against whole cells and their cellular targets remain unknown. 


\section{Conclusion}

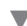

Natural products form a promising source of novel lead structures to address the lack of safe and effective drugs for the treatment of sleeping sickness. Many compounds with a wide variety of structures have been demonstrated to possess high trypanocidal activity and moderate cytotoxicity values towards mammalian cells in vitro. Unfortunately, many of these potential leads have not been investigated further: tests in animal disease models are often lacking and studies focusing on the discovery of the cellular targets and the modes of action of natural products towards trypanosomes are rare. These studies might, however, be of great importance to advance the development of potential new drugs. Once the structure-activity relationships are better understood, derivatives of the lead compound may be developed in order to increase the trypanocidal activity and/or reduce toxic side effects. A network between different disciplines such as biology, medical chemistry and pharmacokinetics is required to move forward in the lead optimisation and avoid that potentially interesting compounds remain in the lab drawers. The discovery of new validated drugs targets and the recent technical progress in the field of natural product chemistry should facilitate this process. Moreover, with the creation of the DNDi, ensuring the coordination of research and development projects between private and public partners, and the new funding opportunities from organisations such as the Gates Foundation, there are more incentives to develop and strengthen natural product based projects related to HAT.

\section{References}

1 World Health Organisation. African trypanosomiasis (sleeping sickness). World Health Organ Fact Sheet, 259, 2006. Available at http:// www.who.int/mediacentre/factsheets/fs259/en/. Accessed May 29, 2010

2 World Health Organisation. Control of human African trypanosomiasis: a strategy for the African region. AFRO, June 2005. AFR/RC55/11. Available at http://www.who.int/trypanosomiasis_african/resources/en/. Accessed May 29, 2010

3 Steverding $D$. The history of African trypanosomiasis. Parasit Vectors 2008; $1: 3$

4 World Health Organisation. Resolution 50.36, 50th World Health Assembly. Geneva: World Health Organisation; 1997

5 Centers of Disease Control and Prevention. CDC's Division of Parasitic Diseases: African trypanosomiasis. July 20th 2009. Avilable at http:// www.dpd.cdc.gov/dpdx/HTML/TrypanosomiasisAfrican.htm. Accessed May 29, 2010

6 Bacchi CJ. Chemotherapy of human African trypanosomiasis. Interdiscip Perspect Infect Dis 2009; 2009: 195040

7 Steverding $D$. The development of drugs for treatment of sleeping sickness: a historical review. Parasit Vectors 2010; 3: 15

8 Soeiro MN, de Castro SL, de Souza EM, Batista DG, Silva CF, Boykin DW. Diamidine activity against trypanosomes: the state of the art. Curr Mol Pharmacol 2008; 1: 151-161

9 Keiser J, Burri C. Physico-chemical properties of the trypanocidal drug melarsoprol. Acta Trop 2000; 74: 101-104

10 Oredsson S, Anehus S, Heby 0 . Inhibition of cell proliferation by DL-a-difluoromethylornithine, a catalytic irreversible inhibitor of ornithine decarboxylase. Acta Chem Scand 1980; 34B: 457-458

11 Yun O, Priotto G, Tong J, Flevaud L, Chappuis F. NECT is next: implementing the new drug combination therapy for Trypanosoma brucei gambiense sleeping sickness. PLoS Negl Trop Dis 2010; 4: e720

12 Wenzler T, Boykin DW, Ismail MA, Hall JE, Tidwell RR, Brun R. New treatment option for second-stage African sleeping sickness: in vitro and in vivo efficacy of aza analogs of DB289. Antimicrob Agents Chemother 2009; 53: 4185-4192

13 ClinicalTrials.gov. Human African trypanosomiasis: first in man clinical trial of a new medicinal product, the fexinidazole. Available at http://www.clinicaltrials.gov/ct2/show/NCT00982904?term=NCT00982904\&rank=1. Accessed May 29, 2010
14 Bridges D, Gould M, Nerima B, Maser P, Burchmore RJS, De Koning HP. Loss of the high affinity pentamidine transporter is responsible for high levels of cross-resistance between arsenical and diamidine drugs in African trypanosomes. Mol Pharmacol 2007; 71: 1098-1108

15 Shahi SK, Krauth-Siegel RL, Clayton CE. Overexpression of the putative thiol conjugate transporter TbMRPA causes melarsoprol resistance in Trypanosoma brucei. Mol Microbiol 2002; 43: 1129-1138

16 Kaminsky R, Maser $P$. Drug resistance in African trypanosomes. Curr Opin Antiinfect Investig Drugs 2000; 2: 76-82

17 McCulloch R. Antigenic variation in African trypanosomes: monitoringprocess. Trends Parasitol 2004; 20: 117-121

18 Vreysen MJ, Saleh KM, Ali MY, Abdulla AM, Zhu ZR, Juma KG, Dyck VA, Msangi AR, Mkonyi PA, Feldmann HU. Glossina austeni (Diptera: Glossinidae) eradicated on the island of Unguja, Zanzibar, using the sterile insect technique. J Econ Entomol 2000; 93: 123-135

19 Gurib-Fakim A. Medicinal plants: traditions of yesterday and drugs of tomorrow. Mol Aspects Med 2006; 27: 1-93

20 Newman DJ, Cragg GM. Natural products as sources of new drugs over the last 25 years. J Nat Prod 2007; 70: 461-477

21 Ioset JR. Natural products for neglected diseases: a review. Curr Org Chem 2008; 12: 643-666

22 Enserink M. If artemisinin drugs fail, what's plan B? Science 2010; 328: 846

23 Samuelsson G, Farah MH, Claeson P, Hagos M, Thulin M, Hedberg O, Warfa AM, Hassan AO, Elmi AH, Abdurahman AD, Elmi AS, Abdi YA, Alin MH. Inventory of plants used in traditional medicine in Somalia. I. Plants of the families Acanthaceae-Chenopodiaceae. J Ethnopharmacol 1991; 35: 25-63

24 Freiburghaus F, Kaminsky R, Nkunya MH, Brun R. Evaluation of African medicinal plants for their in vitro trypanocidal activity. J Ethnopharmacol 1996; 55: 1-11

25 Freiburghaus F, Jonker SA, Nkunya MH, Mwasumbi LB, Brun R. In vitro trypanocidal activity of some rare Tanzanian medicinal plants. Acta Trop 1997; 66: 79-83

26 Hoet S, Opperdoes F, Brun R, Quetin-Leclercq J. Natural products active against African trypanosomes: a step towards new drugs. Nat Prod Rep 2004; 21: 353-364

27 Salem MM, Werbovetz KA. Natural products from plants as drug candidates and lead compounds against leishmaniasis and trypanosomiasis. Curr Med Chem 2006; 13: 2571-2598

28 Setzer WN, Setzer MC. Antitrypanosomal agents from higher plants. In: Williams LAD, editor. Biologically active natural products for the $21 \mathrm{st}$ century. Kerala: Research Signpost; 2006: 47-95

29 Gehrig S, Efferth T. Development of drug resistance in Trypanosoma brucei rhodesiense and Trypanosoma brucei gambiense. Treatment of human African trypanosomiasis with natural products (Review). Int J Mol Med 2008; 22: 411-419

30 Nwaka S, Hudson A. Innovative lead discovery strategies for tropical diseases. Nat Rev Drug Discov 2006; 5: 941-955

31 Berriman M, Ghedin E, Hertz-Fowler C, Blandin G, Renauld H, Bartholomeu DC, Lennard NJ, Caler E, Hamlin NE, Haas B, Böhme U, Hannick L, Aslett MA, Shallom J, Marcello L, Hou L, Wickstead B, Alsmark UC, Arrowsmith C, Atkin RJ, Barron AJ, Bringaud F, Brooks K, Carrington M, Cherevach I, Chillingworth TJ, Churcher C, Clark LN, Corton CH, Cronin A, Davies RM, Doggett J, Djikeng A, Feldblyum T, Field MC, Fraser A, Goodhead I, Hance Z, Harper D, Harris BR, Hauser H, Hostetler J, Ivens A, Jagels K, Johnson D, Johnson J, Jones K, Kerhornou AX, Koo H, Larke N, Landfear S, Larkin C, Leech V, Line A, Lord A, Macleod A, Mooney PJ, Moule S, Martin DM, Morgan GW, Mungall K, Norbertczak H, Ormond D, Pai G, Peacock CS, Peterson J, Quail MA, Rabbinowitsch E, Rajandream MA, Reitter C, Salzberg SL, Sanders M, Schobel S, Sharp S, Simmonds M, Simpson AJ, Tallon L, Turner CM, Tait A, Tivey AR, Van Aken S, Walker D, Wanless D, Wang S, White B, White O, Whitehead S, Woodward J, Wortman J, Adams MD, Embley TM, Gull K, Ullu E, Barry JD, Fairlamb AH, Opperdoes F, Barrell BG, Donelson JE, Hall N, Fraser CM, Melville SE, El-Sayed NM. The genome of the African trypanosome Trypanosoma brucei. Science 2005; 309: 416-422

32 Wirtz E, Clayton C. Inducible gene expression in trypanosomes mediated by a prokaryotic repressor. Science 1995; 268: 1179-1183

33 Wirtz E, Leal S, Ochatt C, Cross GA. A tightly regulated inducible expression system for conditional gene knock-outs and dominant-negative genetics in Trypanosoma brucei. Mol Biochem Parasitol 1999; 99: 89-101

34 Ullu E, Tshudi C, Chakraborty T. RNA interference in protozoan parasites. Cell Microbiol 2004; 6: 509-519 
35 Frearson JA, Wyatt PG, Gilbert IH, Fairlamb AH. Target assessment for antiparasitic drug discovery. Trends Parasitol 2007; 23: 589-595

36 Verlinde CL, Hannaert V, Blonski C, Willson M, Périé JJ, Fothergill-Gilmore LA, Opperdoes FR, Gelb MH, Hol WG, Michels PA. Glycolysis as a target for the design of new anti-trypanosome drugs. Drug Resist Updat 2001; 4: $50-65$

37 Albert MA, Haanstra JR, Hannaert V, Van Roy J, Opperdoes FR, Bakker BM, Michels PA. Experimental and in silico analyses of glycolytic flux control in bloodstream form Trypanosoma brucei. J Biol Chem 2005; 280: 28306-28315

38 Cáceres AJ, Michels PA, Hannaert V. Genetic validation of aldolase and glyceraldehyde-3-phosphate dehydrogenase as drug targets in Trypanosoma brucei. Mol Biochem Parasitol 2010; 169: 50-54

39 Clarkson Jr AB, Grady RW, Grossman SA, McCallum RJ, Brohn FH. Trypanosoma brucei brucei: a systematic screening for alternatives to the salicylhydroxamic acid-glycerol combination. Mol Biochem Parasitol 1981; 3: 271-291

40 Nok AJ. Azaanthraquinone inhibits respiration and in vitro growth of long slender bloodstream forms of Trypanosoma congolense. Cell Biochem Funct 2002; 20: 205-212

41 Minagawa N, Yabu Y, Kita K, Nagai K, Ohta N, Meguro K, Sakajo S, Yoshimoto A. An antibiotic, ascofuranone, specifically inhibits respiration and in vitro growth of long slender bloodstream forms of Trypanosoma brucei brucei. Mol Biochem Parasitol 1997; 84: 271-280

42 Yabu Y, Minagawa N, Kita K, Nagai K, Honma M, Sakajo S, Koide T, Ohta $N$, Yoshimoto A. Oral and intraperitoneal treatment of Trypanosoma brucei brucei with a combination of ascofuranone and glycerol in mice. Parasitol Int 1998; 47: 131-137

43 Yabu Y, Yoshida A, Suzuki T, Nihei C, Kawai K, Minagawa N, Hosokawa T, Nagai K, Kita K, Ohta $N$. The efficacy of ascofuranone in a consecutive treatment on Trypanosoma brucei brucei in mice. Parasitol Int 2003; 52: $155-164$

44 Magae J, Nagai K, Ando K, Tamura G. Differentiation of mouse and human myeloid leukemia cells induced by an antitumor antibiotic, ascofuranone. Agric Biol Chem 1988; 52: 3143-3147

45 Drew ME, Morris JC, Wang Z, Wells L, Sanchez M, Landfear SM, Englund $P T$. The adenosine analog tubercidin inhibits glycolysis in Trypanosoma brucei as revealed by an RNA interference library. J Biol Chem 2003; 278: 46596-46600

46 Ngantchou I, Nkwengoua E, Nganso Y, Nyasse B, Denier C, Hannaert V, Schneider B. Antitrypanosomal activity of polycarpol from Piptostigma preussi (Annonaceae). Fitoterapia 2009; 80: 188-191

47 Fairlamb AH, Blackburn P, Ulrich P, Chait BT, Cerami A. Trypanothione: a novel bis(glutathionyl)spermidine cofactor for glutathione reductase in trypanosomatids. Science 1985; 227: 1485-1487

48 Krauth-Siegel RL, Comini MA, Schlecker T. The tryponothione system. In: Flohé L, Harris JR, editors. Peroxiredoxin systems. New York: Springer; 2007: 231-251

49 Castro H, Tomás AM. Peroxidases of trypanosomatids. Antioxid Redox Signal 2008; 10: 1593-1606

50 Willert EK, Phillips MA. Regulated expression of an essential allosteric activator of polyamine biosynthesis in African trypanosomes. PLoS Pathog 2008; 4: e1000183

51 Comini MA, Guerrero SA, Haile S, Menge U, Lunsdorf H, Flohé L. Validation of Trypanosoma brucei trypanothione synthase as drug target. Free Radic Biol Med 2004; 36: 1289-1302

52 Krieger S, Schwarz W, Ariyanayagam MR, Fairlamb AH, Krauth-Siegel RL, Clayton $C$. Trypanosomes lacking trypanothione reductase are avirulent and show increased sensitivity to oxidative stress. Mol Microbiol 2000; 35: 542-552

53 Wilkinson SR, Horn D, Prathalingam SR, Kelly JM. RNA interfernce identifies two hydroperoxide metabolizing enzymes that are essential to the bloodstream form of the African trypanosomes. J Biol Chem 2003; 278: 31640-31646

54 Fairlamb AH, Henderson GB, Bacchi CJ, Cerami A. In vivo effects of difluoromethylornithine on trypanothione and polyamine levels in bloodstream forms of Trypanosoma brucei. Mol Biochem Parasitol 1987; 24: 185-191

55 Kaminsky R, Zweygarth E. Feeder layer-free in vitro assay for screening antitrypanosomal compounds against Trypanosoma brucei brucei and T. b. evansi. Antimicrob Agents Chemother 1989; 33: 881-885

56 Zweygarth E, Röttcher D. Efficacy of experimental trypanocidal compounds against a multiple drug-resistant Trypanosoma brucei brucei stock in mice. Parasitol Res 1989; 75: 178-182
57 Bacchi CJ, Goldberg B, Garofalo-Hannan J, Rattendi D, Lyte P, Yarlett N. Fate of soluble methionine in African trypanosomes: effects of metabolic inhibitors. Biochem J 1995; 309: 737-743

58 Koide T, Nose M, Inoue M, Ogihara Y, Yabu Y, Ohta N. Trypanocidal effects of gallic acid and related compounds. Planta Med 1998; 64: 27-30

59 Nose M, Koide T, Morikawa K, Inoue M, Ogihara Y, Yabu Y, Ohta N. Formation of reactive oxygen intermediates might be involved in the trypanocidal activity of gallic acid. Biol Pharm Bull 1998; 21: 583-587

60 Wang JC. Cellular roles of DNA topoisomerases: a molecular perspective. Nat Rev Mol Cell Biol 2002; 3: 430-440

61 Liu B, Liu Y, Motyka SA, Agbo EE, Englund PT. Fellowship of the rings: the replication of kinetoplast DNA. Trends Parasitol 2005; 21: 363-369

62 Scocca JR, Shapiro TA. A mitochondrial topoisomerase IA essential for late theta structure resolution in African trypanosomes. Mol Microbiol 2008; 67: 820-829

63 Bakshi RP, Shapiro TA. RNA interference of Trypanosoma brucei topoisomerase IB: both subunits are essential. Mol Biochem Parasitol 2004; 136: $249-255$

64 Kulikowicz T, Shapiro TA. Distinct genes encode type II topoisomerases for the nucleus and mitochondrion in the protozoan parasite Trypanosoma brucei. J Biol Chem 2006; 281: 3048-3056

65 Wang Z, Englund PT. RNA interference of a trypanosome topoisomerase II causes progressive loss of mitochondrial DNA. EMBO J 2001; 20: 4674-4683

66 Торси Z. DNA topoisomerases as targets for anticancer drugs. J Clin Pharm Ther 2001; 269: 405-416

67 Bodley AL, Shapiro TA. Molecular and cytotoxic effects of camptothecin, a topoisomerase I inhibitor, on trypanosomes and Leishmania. Proc Natl Acad Sci USA 1995; 92: 3726-3730

68 Worthen $C$, Jensen $B C$, Parsons M. Diverse effects on mitochondrial and nuclear functions elicited by drugs and genetic knockdowns in bloodstream stage Trypanosoma brucei. PLoS Negl Trop Dis 2010; 4: e678

69 Yardley V, Snowdon D, Croft SL, Hazra B. In vitro activity of diospyrin and its derivatives against Leishmania donovani, Trypanosoma cruzi and Trypanosoma brucei brucei. Phytother Res 1996; 10: 559-562

70 Hoet S, Opperdoes F, Brun R, Adjakidjé V, Quetin-Leclercq J. In vitro antitrypanosomal activity of ethnopharmacologically selected Beninese plants. J. Ethnopharmacol 2004; 91: 37-42

71 Deterding A, Dungey FA, Thompson KA, Steverding D. Anti-trypanosomal activities of DNA topoisomerase inhibitors. Acta Trop 2005; 93: 311316

72 Merschjohann K, Sporer F, Sterverding, Wink M. In vitro effect of alkaloids on bloodstream forms of Trypanosoma brucei and T. congolense. Planta Med 2001; 67: 623-627

73 Mazzini S, Bellucci MC, Mondelli R. Mode of binding of the cytotoxic alkaloid berberine with the double helix oligonucleotides D(AAGAATTCTT) 2 . Biorg Med Chem 2003; 11: 505-514

74 Stiborova M, Simanek V, Frei E, Hobza P, Ulrichova J. DNA adduct formation from quaternary benzo[c]phenanthridine alkaloids sanguinarine and chelerythrine as revealed by the ${ }^{32} \mathrm{P}$-postlabeling technique. Chem Biol Interact 2002; 140: 1096-1101

75 Zhang FL, Casey PJ. Protein prenylation: molecular mechanisms and functional consequences. Annu Rev Biochem 1996; 65: 241-269

76 Eastman RT, Buckner FS, Yokoyama K, Gelb MH, Van Voorhis WC. Fighting parasitic disease by blocking protein farnesylation. J Lipid Res 2006; 47: 233-240

77 Ali BR, Pal A, Croft SL, Taylor RJ, Field MC. The farnesyltransferase inhibitor manumycin $\mathrm{A}$ is a novel trypanocide with a complex mode of action including major effects on mitochondria. Mol Biochem Parasitol 1999; 104: 67-80

78 Zhou J, Giannakakou P. Targeting microtubules for cancer chemotherapy. Curr Med Chem Anticancer Agents 2005; 5: 65-71

79 Morgan RE, Werbovetz KA. Selective lead compounds against kinetoplastid tubulin. Adv Exp Med Biol 2008; 625: 33-47

80 Ochola DO, Prichard RK, Lubega GW. Classical ligands bind tubulin of trypanosomes and inhibit their growth in vitro. J Parasitol 2002; 88: 600-604

81 Frearson JA, Brand S, McElroy SP, Cleghorn LA, Smid O, Stojanovski L, Price HP, Guther ML, Torrie LS, Robinson DA, Hallyburton I, Mpamhanga CP, Brannigan JA, Wilkinson AJ, Hodgkinson M, Hui R, Qiu W, Raimi OG, van Aalten DM, Brenk R, Gilbert IH, Read KD, Fairlamb AH, Ferguson MA, Smith DF, Wyatt PG. N-myristoyltransferase inhibitors as new leads to treat sleeping sickness. Nature 2010; 464: 728-732

82 el Kouni MH. Potential chemotherapeutic targets in the purine metabolism of parasites. Pharmacol Ther 2003; 99: 283-309 
83 Lee SH, Stephens JL, Englund PT. A fatty-acid synthesis mechanism specialized for parasitism. Nat Rev Microbiol 2007; 5: 287-297

84 Naula C, Parsons M, Mottram JC. Protein kinases as drug targets in trypanosomes and Leishmania. Biochim Biophys Acta 2005; 1754: 151 159

85 Agüero F, Al-Lazikani B, Aslett M, Berriman M, Buckner FS, Campbell RK, Carmona S, Carruthers IM, Chan AW, Chen F, Crowther GJ, Doyle MA, Hertz-Fowler C, Hopkins AL, McAllister G, Nwaka S, Overington JP, Pain A, Paolini GV, Pieper U, Ralph SA, Riechers A, Roos DS, Sali A, Shanmugam $D$, Suzuki T, Van Voorhis WC, Verlinde CL. Genomic-scale prioritization of drug targets: the TDR Targets database. Nat Rev Drug Discov 2008; 7: $900-907$

86 Kubata BK, Nagamune K, Murakami N, Merkel P, Kabututu Z, Martin SK, Kalulu TM, Huq M, Yoshida M, Ohnishi-Kameyama M, Kinoshita T, Duszenko M, Urade Y. Kola acuminata proanthocyanidins: a class of antitrypanosomal compounds effective against Trypanosoma brucei. Int J Parasitol 2005; 35: 91-103

87 Adamson RH, Zaharevitz DW, Johns DG. Enhancement of the biological activity of adenosine analogs by the adenosine deaminase inhibitor 2'deoxycoformycin. Pharmacology 1977; 15: 84-89
88 Vodnala SK, Ferella M, Lundén-Miguel H, Betha E, van Reet N, Amin DN, Oberg B, Andersson B, Kristensson K, Wigzell H, Rottenberg ME. Preclinical assessment of the treatment of second-stage African trypanosomiasis with cordycepin and deoxycoformycin. PLoS Negl Trop Dis 2009; 3: e495

89 Mamani-Matsuda M, Rambert J, Malvy D, Lejoly-Boisseau H, Daulouède $S$, Thiolat D, Coves S, Courtois P, Vincendeau P, Mossalayi MD. Quercetin induces apoptosis of Trypanosoma brucei gambiense and decreases the proinflammatory response of human macrophages. Antimicrob Agents Chemother 2004; 48: 924-929

90 Kuettel S, Mosimann M, Mäser P, Kaiser M, Brun R, Scapozza L, Perozzo R. Adenosine inase of $T$. $b$. rhodesiense identified as the putative target of 4-[5-(4-phenoxyphenyl)-2H-pyrazol-3-yl]morpholine using chemical proteomics. PLoS Negl Trop Dis 2009; 3: e506

91 Denise H, Giroud C, Barrett MP, Baltz T. Affinity chromatography using trypanocidal arsenical drugs identifies a specific interaction between glycerol-3-phosphate dehydrogenase from Trypanosoma brucei and Cymelarsan. Eur J Biochem 1999; 259: 339-346 